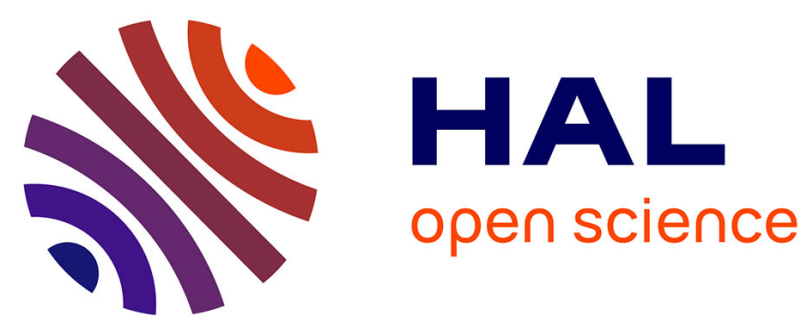

\title{
Competition and collusion on the world coffee market
} Eric Giraud-Héraud, Chantal Le Mouël, Vincent Réquillart

\section{To cite this version:}

Eric Giraud-Héraud, Chantal Le Mouël, Vincent Réquillart. Competition and collusion on the world coffee market. 36. Seminar: Food policies and the food marketing chain, Sep 1994, Reading, United Kingdom. hal-02283452

\section{HAL Id: hal-02283452 \\ https://hal.science/hal-02283452}

Submitted on 7 Jun 2020

HAL is a multi-disciplinary open access archive for the deposit and dissemination of scientific research documents, whether they are published or not. The documents may come from teaching and research institutions in France or abroad, or from public or private research centers.
L'archive ouverte pluridisciplinaire HAL, est destinée au dépôt et à la diffusion de documents scientifiques de niveau recherche, publiés ou non, émanant des établissements d'enseignement et de recherche français ou étrangers, des laboratoires publics ou privés.

\section{(ㅇ)(1) $\$$}

Distributed under a Creative Commons Attribution - NonCommercial - NoDerivatives 44.0 
'FOOD POLICY AND THE FOOD CHAIN, STRUCTURES AND INTER-RELATIONSHIPS"

Reading, U. K., September 19-21, 1994

\section{COMPETITION AND COLLUSION ON THE WORLD COFFEE MARKET}

Eric Giraud-Héraud*, Chantal Le Mouël**,

Vincent Réquillart ${ }^{*}$

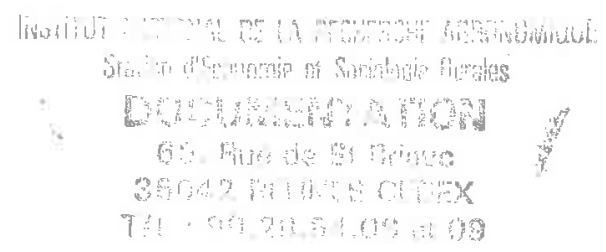

July 1994

- INRA-ESR, 78850 GRIGNON, France

- INRA-ESR, 65, Rue de Saint-Brieuc 35042 RENNES Cedex, France

\section{ary \\ no 10}





\section{INTRODUCTION}

For much of the last quarter century, world coffee trade has been controlled by a group of exporters and importers through a series of International Coffee Agreements (ICAs) under the authority of the International Coffee Organisation (ICO). Each coffee year, the ICA set sales volumes and indirectly regulated world coffee prices. Under the quota system, each producing country was given a percentage share of the market for importing member countries.

But disputes over coffee sales to non-ICA member importing countries and over the availability of the different types of coffee led the ICO to drop export quotas in July $1989{ }^{1 .}$ Despite several negotiation rounds between exporters and importers, there has been na resolution. Without quotas, major exporters began aggressively to sell their coffee, resulting in a steep fall in the world coffee prices. Thus since 1989, exporting countries have suffered from a sharp decrease in their coftee exports receipts. For example while in 1985-86, the ICO producing countries exported 4.1 million tons of coffee corresponding to a 14 billion $\$$ export value, in 1989-90 the 4.9 million tons of exports accounted for only 6.6 billion $\$$.

Because an agreement involving both exporters and importers could not be reached, concerns over major exporters earnings led these lafters to investigate the possibility of cooperating in order to restore higher colfee price levels on the world market. Following several meetings, major coffee producing countries agreed on a new retention scheme in September 1993. More precisely, during a meeting held in Brasilia, twenty-seven producing countries (accounting for $80 \%$ of the world coffee production) agreed on retaining 10 to $20 \%$ of their sales on the world market until coffee prices recover higher levels. Between October 1993 and May 1994, world prices of coffee have risen by about $35 \%$.

The inability of the ICA quota system to deal adequately with the problem of availability of the different types of coffee has revealed as a main factor originating the breakdown of the former Agreement. In fact, two most important species of coffee are traded on the world market: arabica ${ }^{2}$ (mainly produced in Brazil and Colombia and accounting for $75 \%$ of the world coffee exports) and robusta (for which major producers are Indonesia and African countries). Under the ICA quota system, each country was allocated an annual export quota but adjustment was sometimes necessary during the year according to whether the market was judged to be over or under supplied. Although the various ICAs allowed the adjustments of export quotas to be selective regarding the coffee type over or

\footnotetext{
1 For a detalled presentation of the history of the world collee market, the background for the collee Agreernents and the content of 2 the various ICAs, see Daviron (1985), Daviron and Levin (1986), Mwandha et al. (1985) and Delaports (1993). 2 According
} 
under supplied, in practice opposition from producers and technical problems prevented this scheme from operating. Then, any increase or reduction in export quotas was done on a country-by-country basis using pre-set share, with little regard for the type of coffee desired by importers.

Now, major producing countries of arabica and robusta coffees are involved in the newly-adopted export retention scheme. Hence, this further arrangement will still face this context of differentiated products. So, the objective of this paper is to investigate whether this product differentiation may enhance or weaken the sustainability of this cooperative agreement.

One important feature of the new arrangement on the coffee market is that importing countries are no longer involved as'they were in the old ICAs. Therefore, while before 1989 coffee exports were controlled by importing countries (through the system of Certificates of Origin), the adopted retention scheme provides no mean to control the quantity exported by each producing countries. Moreover, since the retention scheme is not under the authority of the ICO, nor of any other public organ, only self-discipline behaviours from exporting countries could permit such a cooperative agreement to be sustained.

The idea among which some cooperation could be reached among coffee exporting countries through self-discipline seems consistent with the main characteristics of the world coffee market. Firstly, the world demand for coffee is relatively inelastic ${ }^{3}$. Secondly, the world coffee market is highly concentrated on the export supply side since the four largest exporters (Brazil, Colombia, Indonesia and Ivory-Coast) contributes about $60 \%$ to the world exports. Thirdly in many exporting countries, governments exert control on coffee growing and trading through public agencies ${ }^{4}$. Hence, although in almost all exporting countries coffee is produced by a great number of smaltholders, the world coffee export supply seems to be imperfectly competitive.

This has led a number of authors to address the possibility of imperfect competition in the world coffee export market (e.g. Epps, 1975 ; Sengupta and Wang, 1991; Karp and Perloff, 1993). While these studies provide some insights about the strategic behaviour of the main coffee exporting countries, they all relate to the world coffee market under the ICAs export quota system and do not consider the product differentiation dimension.

\footnotetext{
3 Estimates of the direct price elasticity of the world demand for colfee are comprises, among authors, between - 0.1 and -0.7 (see Okunade, 1992).

4 For more debails on this point, see Marshall (1983).
} 
Then, our concem is to analyse whether self-discipline among coffee exporters (through the retention of a percentage share of their respective sales on the world market) can be sustained in a context of product differentiation. We use recent work in game theory which has demonstrated how cooperative outcomes can be sustained when the game is played repeatedly, defectors are punished, but agents play non-cooperatively (e.g. Green and Porter, 1984; Abreu, Pearce and Stachetti, 1986; Riezman, 1991). Then, we assume that coffee exporting countries do not formally cooperate but adopt strategles that can lead to cooperation over time. Thus, our approach of cooperation relates to the trigger strategy framework as defined by Friedman (1971). We adopt a quantity competition scheme. Throughout the repeated game, each coffee exporting country can either retain a percentage share of its sales on the world market (as required by the adopted retention scheme) or cheats on this cooperative equilibrium. But any defection from tacit cooperation is punished by a reversion to Cournot-Nash equilibrium ${ }^{5}$. In addition, we assume that the world coffee demand is vertically differentiated with arabica as the high quality product and robusta as the low one ${ }^{6}$.

Supergame models of collusion have been used to study product differentiation in recent works. Deneckere (1983) and Majerus (1988) study the relative efficiency of price vs. quantity competition in cartels composed of firms selling differentlated products. Chang (1991) and Ross (1992) analyse the effects of different levels of product differentiation on cartel stability. They show that increased differentiation could enhance cartel stability. However, their results correspond to the case of a cartel of two identical firms, in the context of either a quadratic utility model or an address model of differentlation, implying a rather different situation from the one prevailing on the world coffee market.

The paper is organised as follows. In section 2, we present the basic model. Section 3 focus on whether cooperation can be sustained in a context of vertical product differentiation. Two different retentlon schemes are successively examined: i) the percentage share retained is different among countries according to the quality product they sell and ii) the percentage share retained is equal for all producing countries. Finally, in section 4 issues for the world coffee trade are discussed in light of the theoretical predictions.

\footnotetext{
5 Desplte casual evidence suggests that coffee exporting countries cannot adjust thelr production instantaneously, adjusternents in the quantiltes sold on the world market may stem Irom ajustments in hventories since major colfee exporting countries (such as Brazll and Colombia) maintain large stockpiles.

6 Generally, collee qualty is judged on the characteristics of the row bean, the roested been and the llquor, But the liquor stage constlutes the tue Indication of the colfee beverage qualites for consumers. The term "hard" Indlcatas a rank favour that makes the cup quality rather low. By contrast, "sotr" reters to a strong and acid (in the desirable sense flavour corresponding to a higher quality cup. Arableas are generally termed "sotte while robustas are called hard" (See Mwandha at al., 1985).
} 


\section{THE MODEL}

Let consider $n$ countries producing two fixed qualities $k_{1}$ and $k_{2}$ (with $0<k_{1}<k_{2}$ ) of a differentiated product. $N$ denotes the set of producing countries $(n=c a r d(N))$ while $N_{j}(j=I, 2)$ is the set of quality $k_{j}$ producing countries $\left(N=N_{1} U N_{2}\right.$ and $\left.n_{j}=\operatorname{card}\left(N_{j}\right)\right)$. We assume that each producing country produces only one quality of the product $\left(N_{1} \cap N_{2}=\varnothing\right)$. We adopt the view of quantity setting producing countries which consider the Cournot game as an infinitely repeated game.

$q_{i j}(\tau)$ is the quantity of quality product $k_{j}(j=1,2)$ supplied by country $i\left(i=I_{,}, n_{j}\right)$ in period $\tau$. Then $q(\tau)=\left(q_{i j}(\tau)\right)_{i=I, n_{j}, j=l .2}$ is the vector of national supply quantities in period $\tau$. Each producing country has a quadratic cost which is assumed to vary according to the quality good produced. Then, the total production cost of country $i$ producing quality $k_{j}$ is written as:

$$
C_{j}\left(q_{i j}(\tau)\right)=c_{j} q_{i j}(\tau)^{2} \quad i=l, n_{j} ; j=l, 2
$$

In period $\tau$, each country producing quality $k$, of the differentiated product faces the inverse demand function $p_{j}(q(\tau)),(j=l, 2)$. Hence, the profit of each producing country $i$ is given by:

$$
\pi_{i j}(q(\tau))=p,(g(\tau)) q_{i j}-C_{,}\left(q_{i j}\right) i=l, n_{j} \quad j=1,2 .
$$

On the demand side, a vertical product differentiation model is adopted. This kind of model has been widely used in the literature on product differentiation (e.g. Mussa and Rosen, 1978 ; Motta, 1993) and its main characteristics are well-known. As part of the basic hypothesis, is that consumers differ in their tastes and face various qualities of the product. Tastes of consumers are described by the parameter $\theta \in[\underline{\theta} ; \bar{\theta}], \theta$ being uniformly distributed. $\underline{\theta}$ and $\bar{\theta}$ represent consumers endowed with respectively the lowest and the highest taste for quality in the economy. A consumer characterised by the taste parameter $\theta$ buys one unit of one quality of the product in order to maximise its utility defined as:

$$
U_{\theta}\left(k_{j}, p_{j}\right)=\theta k_{j}-p_{j}
$$

However if $U_{\theta}\left(k_{j}, p_{j}\right) \leq 0$ for $j=1,2$, then the consumer $\theta$ does not buy the differentiated product. Hence, in period $\tau$, the inverse demand functions of each quality $k_{j}$ of the differentiated product may be written as:

$$
\left.\begin{array}{l}
p_{1}(q(\tau))=k_{1}\left(\bar{\theta}-t\left(Q_{1}(\tau)+Q_{2}(\tau)\right)\right) \\
p_{2}(q(\tau))=k_{2}\left(\bar{\theta}-t\left(\lambda Q_{1}(\tau)+Q_{2}(\tau)\right)\right)
\end{array}\right\}
$$


where $Q_{j}(\tau)=\sum_{i=1}^{n_{1}} q_{i j}(\tau)$ is the aggregate supply of quality product $k_{j}$ in period $\tau$. The ratio $\lambda=k_{1} / k_{2}$, which lies in the range $[0,1]$, serves as a measure of the degree of product differentiation. While $t=\bar{\theta}-\underline{\theta}$ indicates the degree of heterogeneity among consumers.

We assume that countries view the quantity game as an infinitely repeated game. Hence, the problem facing each country is:

$$
\max _{q_{i j}} \sum_{\tau=0}^{\infty} \delta^{\tau} \pi_{i j}(q(\tau))
$$

where the actual discount rate $\delta \in[0,1]$ is equal for all producing countries. Let suppose that a set of producing countries $C(C \in N)$ adopt trigger strategies (see Friedman, 1971) which require them to retain a percentage share of their production unless there is evidence that someone is cheating on the retention scheme. Any defection from the production retention scheme is punished by an infinite reversion to Cournot-Nash equilibrium quantities. Then, the retention scheme is sustained within $C$ as long as it never pays a country belonging to $C$ to defect. That is, if the one period gain from defection is less than the discounted stream losses from having Cournot-Nash equilibrium for ever, then the retention scheme is chosen. At time 0 , each producing country $r$ belonging to $C$ will choose to adopt the retention scheme if ${ }^{7}$ :

$$
\pi_{\eta}^{d}-\pi_{\eta}^{c}<\sum_{\tau=1}^{\bar{\delta}} \delta^{+}\left(\pi_{\eta}^{c}-\pi_{\eta}^{m}\right)
$$

where $\pi_{j}^{c}$ denotes the profit of country $r$ (producing quality product $k_{j}$ ) when the retention scheme holds within $C . \pi_{\eta}^{d}$ is the profit of country $r$ resulting from cheating (i.e. from producing its best response quantity when other countries leave their production unchanged). Finally $\pi_{n}^{m}$ is the profit of country $r$ resulting from the reversion to CournotNash equilibrium quantities. Hence, the left-hand side of (3) gives the one-period expected gain of country $r$ to cheating by producing its best response quantity in period 0 . The right-hand side of (3) gives the expected discounted loss that occur because from the next period on, Cournot-Nash quantities will be produced instead of smaller quantities.

From condition ( () , it can be seen that the retention scheme can be sustained by tacit cooperation within a set $C$ of producing countries, provided the actual discount rate $\delta$ is not too small i.e. if:

\footnotetext{
7 In the following, arguments of the countries' prottt functions are dropped for simpllcity.
} 


$$
\text { (HI) } \forall r \in C \quad \delta>\delta^{\circ}=\frac{\pi_{r, j}^{d}-\pi_{r, j}^{c}}{\pi_{r, j}^{d}-\pi_{r, j}^{m}}
$$

where $\delta^{*}$ is the critical discount rate. Thus, it can be deduced from condition (HI) that lower levels of $\delta$ " correspond to more likely cooperation among producing countries ${ }^{8}$. However, in addition to condition (HI), we may ensure the punishments to be credible. That is if defection does occur, other countries involved in the collusion $C$ will actually carry out the punishment. In the literature on cartel stability, several authors have underlined the need to distinguish the cases where the punishments are effectively credible i.e. the cases where it is profitable for the cheated collusion to punish the defector (e.g. Farell and Maskin, 1989 ; Rotschild, 1993). Here, we will say that punishments are not credible if:

$$
\text { (H2) } \forall i \in C-\{r\} \quad \pi_{i j}^{m}<\pi_{i j}^{v}
$$

where $\pi_{i j}^{v}$ is the profit of country $i$ being cheated by country $r$. Condition ( $\mathrm{H}_{2}$ ) says that if for each producing country in $C-\{r\}$, the reversion to Cournot-Nash equilibrium is less profitable than going along with the cooperative equilibrium, then the cheated collusion will not carry out the punishment. In the following we will consider that punishments are "credible" if and only if they are not "non-credible". Of course, this is a simplified definition of credibility. A more general definition would require to investigate all the cases where a sub-set of $C-\{r\}$ could be negatively affected by a reversion to Cournot-Nash equilibrium.

\section{SUSTAINABILITY OF COLLUSIONS AND PRODUCT DIFFERENTIATION}

In this section, we examine the impact of product differentiation on the sustainability of two kinds of collusion: i) symmetric collusions involving countries producing the same quality product and ii) asymmetric collusions formed by countries producing different quality products. In all cases, tacit cooperation takes the form of a production retention scheme. In the first case, as cooperation comes onto identical countries, we assume that the retention scheme corresponds to the Pareto optimum which maximises the sum of profits of cooperating countries. In the second case, the retention scheme requires that each involved country retains the same percentage share of her Coumot-Nash quantity. In the following, we hypothesise that the ratio of the cost parameter to the quality parameter is a constant

\footnotetext{
8 Assuming that $\pi_{\eta}^{d}>\pi_{\eta}^{c}$ (i,e cheating is profitable in a one-shot setting), it can be seen thet, as scon as $\pi_{\eta}^{m}>\pi_{\eta}^{c}, \delta$ " is greater than 1 , In that case lor each producing country in $C$. the Nash equilibrium is more prolitable than the cooperative equilibrlum. Hence, the collusion $C$ cannot be sustained, Salant, switzer and Reynolds (1983) have shown that in the case of a model "à la Cournor" with an homogeneous product, mergers could reduce the aggregate probit of lims involved in the markel,
} 
(i.e. $\left.a_{j}=c, / a_{,}=a, j=I, 2\right)$. The derivation of quantities and prices corresponding to the various equilibria is reported in appendix. Analytical results correspond to the most general case which allows to perform simulations in order to examine how the cheaters' critical discount rates are sensitive to various parameters.

\subsection{Sustainability of symmetric collusions}

The concem here is to investigate the sustainability of collusions involving identical producing countries. Two cases are outlined: i) the homogeneous product case where $C=N$, implying that countries in $C$ are not competing with other quality-type producing countries and ii) quality-type collusions (i.e. $C=N_{1}$ or $C=N_{2}$ ) where countries in $C$ face competition from countries producing the other quality product. In other words, what is pointed out in this last case is whether cooperation in the form of a non-uniform retention scheme (In the sense that, depending on whether countries belong to $C$ or not, they are not required to retain the same percentage share of their production) is supportable.

\subsubsection{The homogeneous product case $\left(k_{1}=k_{2}=k\right)$}

When the product is homogeneous, the inverse demand function is written $p(Q)=k(\bar{\theta}-1 Q)$, where $Q$ is the aggregate supply. Assuming $C=N$, the countries' profits corresponding to the various equilibria are:

$$
\left.\begin{array}{ll}
\pi_{,}^{c}=\frac{1}{4(a+n t)} k \bar{\theta}^{2} & i=I, n \\
\pi_{r}^{d}=\frac{[2 a+(n+1) t]^{2}}{16(a+t)(a+n t)^{2}} k \bar{\theta}^{2} & r=I, n \\
\pi_{r}^{\nu}=\frac{\left[2 a^{2}+2(n+1) t a+(n+1) t^{2}\right]}{8(a+t)(a+n t)^{2}} k \bar{\theta}^{2} & i=I, n \neq r \\
\pi_{i}^{m}=\frac{(a+t)}{[2 a+(n+1) t]^{2}} k \bar{\theta}^{2} & i=I, n
\end{array}\right\}
$$

Hence, the critical discount rate (which applies to all producing countries) is written as:

$$
\delta_{\lambda=1}^{*}(a, t, n)=I-\frac{V(a, t, n)}{V(a, t, n)+W(a, t, n)}
$$

with 


$$
\begin{aligned}
& V(a, t, n)=\downarrow(a+t)(a+n t) \\
& W(a, t, n)=[2 a+(n+1) t]^{2}
\end{aligned}
$$

One may easily verify that:

$$
\begin{aligned}
\forall a, t, n \in R^{+}, \quad & 0<\delta_{\lambda=1}^{*}(a, t, n)<1 \\
& \frac{\partial \delta_{i=1}^{*}(a, t, n)}{\partial t}>0 \text { and } \lim _{t \rightarrow 0} \delta_{\lambda=1}^{*}(a, t, n)=\frac{I}{2} \\
& \frac{\partial \delta_{\lambda=1}^{*}(a, t, n)}{\partial n}>0
\end{aligned}
$$

Therefore, recalling that higher levels of the critical discount rate indicate that cooperation is less likely to be supportable, the probability for the retention scheme to be sustained is decreasing in the number of involved countries as well as in the degree of heterogeneity within the consumer group.

Moreover, assuming a varying cost parameter yields:

$$
\forall a, t, n \in R^{+}, \quad \frac{\partial \delta_{\lambda=t}^{*}(a, t, n)}{\partial a}<0
$$

Then, the critical discount rate is decreasing in costs, implying that higher costs act as favouring the sustainability of the collusion.

Finally, let notice that in this homogeneous product case, punishments are credible since the profit of a cheated country $\left(\pi_{i}^{\nu}\right)$ is always lower than her Cournot-Nash equilibrium profit $\left(\pi_{i}^{m}\right)$.

\subsubsection{The quality-type collusions case}

It is now assumed that the product is differentiated. Thus two groups of different countries are competing on the market for the differentiated product. The first one involves $n_{1}$ countries producing the low quality product $k_{1}$ while the second one is composed of $n_{2}$ countries producing the high quality product $k_{2}$. 
Then, our objective is to examine the relationship between product heterogeneity and the sustainability of cooperation within each country group facing competition from the other country group (i.e. $C=N, j=1,2$ ). The critical discount rate for each country producing quality $k_{j}$ is denoted $\delta_{a}^{\prime}\left(\lambda, I, n_{1}, n_{2}\right)$. Hence, the computation of the critical discount rates corresponding to both qualities leads to the following interesting result:

$$
\delta_{a}^{\prime *}(\lambda, t, l, s)=\delta_{a}^{2^{* *}}(\lambda, t, s, l) \quad \forall \lambda, l \in[0, l], \forall I, s \in R^{*+}
$$

Therefore, in the case of two fixed qualities and assuming that the actual discount rate is identical for all countries, the incentive to cheat on each quality-type collusion is equivalent, provided cheated collusions have the same size ( $l$ in the above equation) and each competes with an equal-sized other quality-type collusion ( $s$ in the above equation). Hence, in this case, asymmetry among countries (according to the respective quality they produce) does not affect the probability for cooperation to be sustained among identical countries.

Figure 1 illustrates the relationship between product differentiation (as measured by $\lambda)$ and the critical discount rates $\delta_{a}^{\prime *}\left(\lambda_{1} t_{1} n_{1}, n_{2}\right)$. Notice that it is a positive monotonic relationship, indicating that the more homogeneous the products are the less likely the quality-type collusions are sustainable. Hence, product differentiation acts as increasing the probability for cooperation to be sustained among identical countries.

Figure 1 also shows that, as in the previous case, greater consumer heterogeneity (i.e. increasing parameter $\hat{f}$ implies stronger incentive for countries to cheat on cooperation. Particularly it can be noticed that for high levels of $t(t=2$ on figure 1) a certain degree of product differentiation is needed for cooperation become more profitable than noncooperation (for $t=2, \quad \delta_{a, 1}^{\prime *}>1$, that is the cooperative profit is lower than the CournotNash profit, as long as $\lambda$ remains greater than 0.85 ). On the other hand, condition ( $\mathrm{H} 2$ ) ensuring the non-credibility of punishments never holds. 
Figure 1 : The relationship between product differentiation and the critical discount rates (for various degrees of heterogeneily among consumers)

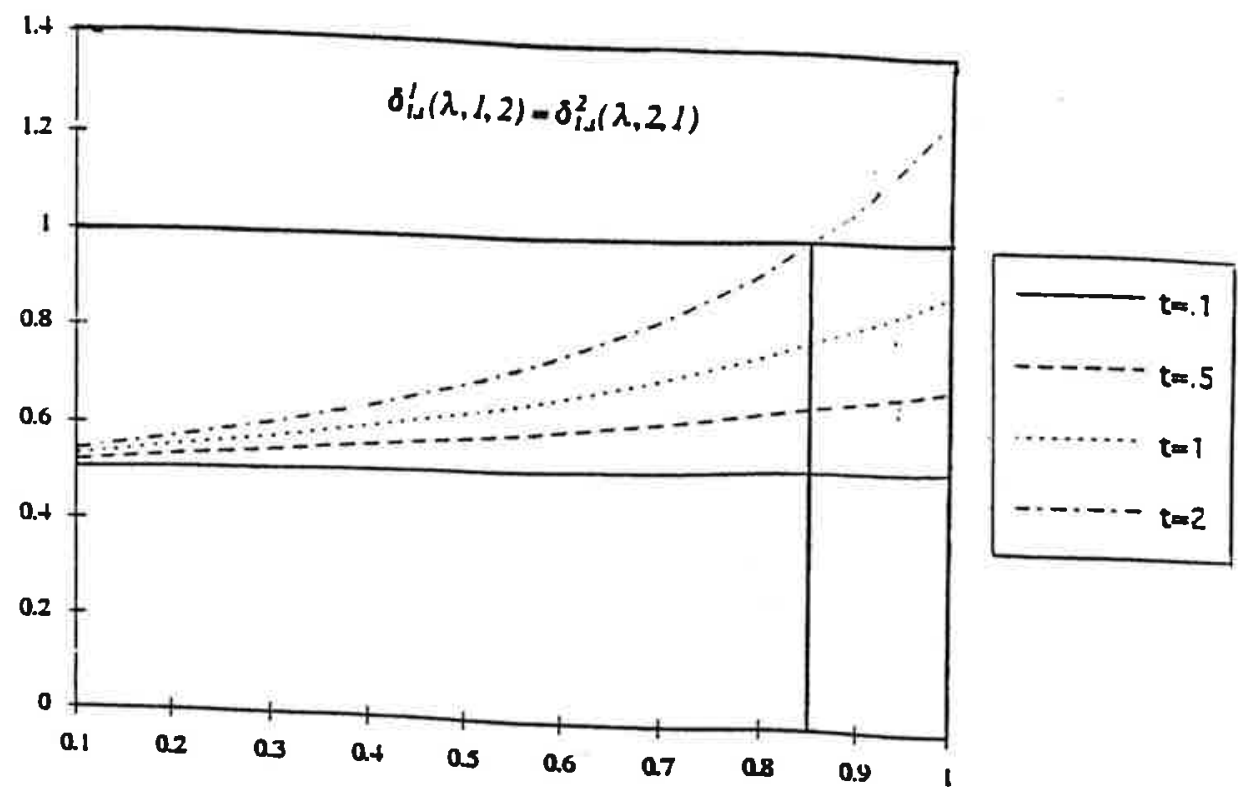

NB : For $a=1$ 
To summarise, the main point which has been pointed out is that product differentiation favours cooperation, in the form of a non-uniform (i.e. quality specific) retention scheme, to be sustained among countries producing the same quality product. The following paragraph emphasises that product differentiation has rather different effects regarding the sustainability of a collusion which involves differentiated countries adopting a uniform retention scheme.

\subsection{Sustainability of asymmetric collusions}

We assume that all countries adopt trigger strategies which require to retain a percentage share of their respective Coumot-Nash quantity productions. The retention percentage share $\mu,(\mu \in[0, I])$ is determined so that:

$$
\mu=\operatorname{Max}_{\mu}\left[\alpha\left(\sum_{i=1}^{n_{1}} \pi_{11}\left(p_{1}\left(\mu Q_{i}^{m}, \mu Q_{2}^{m}\right), \mu q_{11}^{m}\right)\right)+(1-\alpha)\left(\sum_{i=1}^{n_{1}} \pi_{i 2}\left(p_{2}\left(\mu Q_{i}^{m}, \mu Q_{2}^{m}\right), \mu q_{12}^{m}\right)\right)\right]
$$

where $Q_{1}^{m}$ and $Q_{2}^{m}$ denote respectively the total production of quality $I$ and quality 2 products at Cournot-Nash equilibrium, while $q_{11}^{m}$ and $q_{12}^{m}$ are the corresponding quantities in countries $i$. By considering a weighted sum of profits, we assume implicitly that one Pareto optimum is selected within the set of possible Pareto equilibria. Therefore, the weight $\alpha(\alpha \in[0,1])$ indicates the degree of power exerted by each country group when negotiating the retention percentage share.

Resolving the first-order condition of the optimisation program (6) yields the following expression for the optimal percentage share $\mu^{*} 9$ :

$$
\mu^{*}=\left[\frac{\lambda \alpha Q_{1}^{m}+(I-\alpha) Q_{2}^{m}}{\lambda t Q_{1}^{m} Q_{2}^{m}+\left(t+\frac{a}{n}\right)\left[\lambda \alpha\left(Q_{1}^{m}\right)^{2}+(I-\alpha)\left(Q_{2}^{m}\right)^{2}\right]}\right] \frac{\bar{\theta}}{2}
$$

Then, figures 2 and 3 illustrate how the critical discount rates for both low quality $\left(\delta_{a, 1}^{\prime *}\left(\lambda_{1} n_{1}, n_{2}\right)\right.$ in figure 2) and high quality $\left(\delta_{a, 1}^{r^{*}}\left(\lambda, n_{1}, n_{2}\right)\right.$ in figure 3) producing countries vary when product homogeneity increases. Simulations have been carried out for the polar cases within the set of possible Pareto optima ( $\alpha=0$ indicating that the whole bargaining power is given to the high quality country group and $\alpha=/$ corresponding to the opposite situation). Hence, simulation results allow us to make three points about the relationship between product differentiation and the sustainability of this kind of collusion.

\footnotetext{
9 The weighted sum of prolits is a concave function of $\mu$
} 
Firstly, the incentive to cheat on the cooperative equilibrium is always greater for high quality producing countries $\left(\delta_{l, 1}^{2^{*}}\left(\lambda, n_{l}, n_{2}\right) \geq \delta_{l, l}^{l \cdot}\left(\lambda, n_{1}, n_{2}\right)\right)$, whatever degree of product differentiation. Moreover, when the product is non homogeneous (i.e. $\lambda<1$ ), the less bargaining power they get in the retention share decision process, the more high quality producing countries are incented to cheat on the retention scheme (on figure 3 , it can be seen that the critical discount rates corresponding to $\alpha=l$ are always greater than the one obtained for $\alpha=0$ whatever the level of $\lambda$ and the values of $n_{1}, n_{2}$ ).

Secondly, product differentiation induces opposite effects regarding the respective incentive to cheat for low quality and high quality producing countries. As illustrated by figure 2 , more product heterogeneity deters low quality producing countries to cheat on the cooperative equilibrium (since $\delta_{l, l}^{\prime \prime}\left(\lambda_{1}, n_{1}, n_{2}\right)$ is increasing in $\lambda$ ). In other words, from the low quality country group's point of view, product differentiation favours the retention scheme arrangement to be sustained over time. At reverse, figure 3 shows that higher levels of product differentiation increases the critical discount rate for high quality producing countries $\left(\delta_{l .1}^{2^{*}}\left(\lambda, n_{1}, n_{2}\right)\right.$ is decreasing in $\left.\lambda\right)$, suggesting a stronger incentive to cheat on the cooperative equilibrium. Thus, according to the high quality country group, product differentiation lowers the probability for cooperation to be sustained.

Thirdly, comparing figures 2 and 3 , it appears that, in a context of differentiated products, the highest probability for the collusion to be sustained over time is obtained when the high quality country group is given the power to set alone the retention share according to its own profit maximisation (i.e. when $\alpha=0$ ). Therefore, it seems that such a collusion, involving countries producing a vertically differentiated product, is more likely to be supportable when high quality producing countries have strong bargaining power in the retention share decision process (i.e. when $\alpha$ is low). The main reason for this result is that self-discipline is always profitable for low quality producing countries while the high quality country group has often strong incentive to cheat on the cooperative equilibrium. 
Figure 2 : The relationship between product differentiation and the critical discount rate for

0.6 low quality producing countries

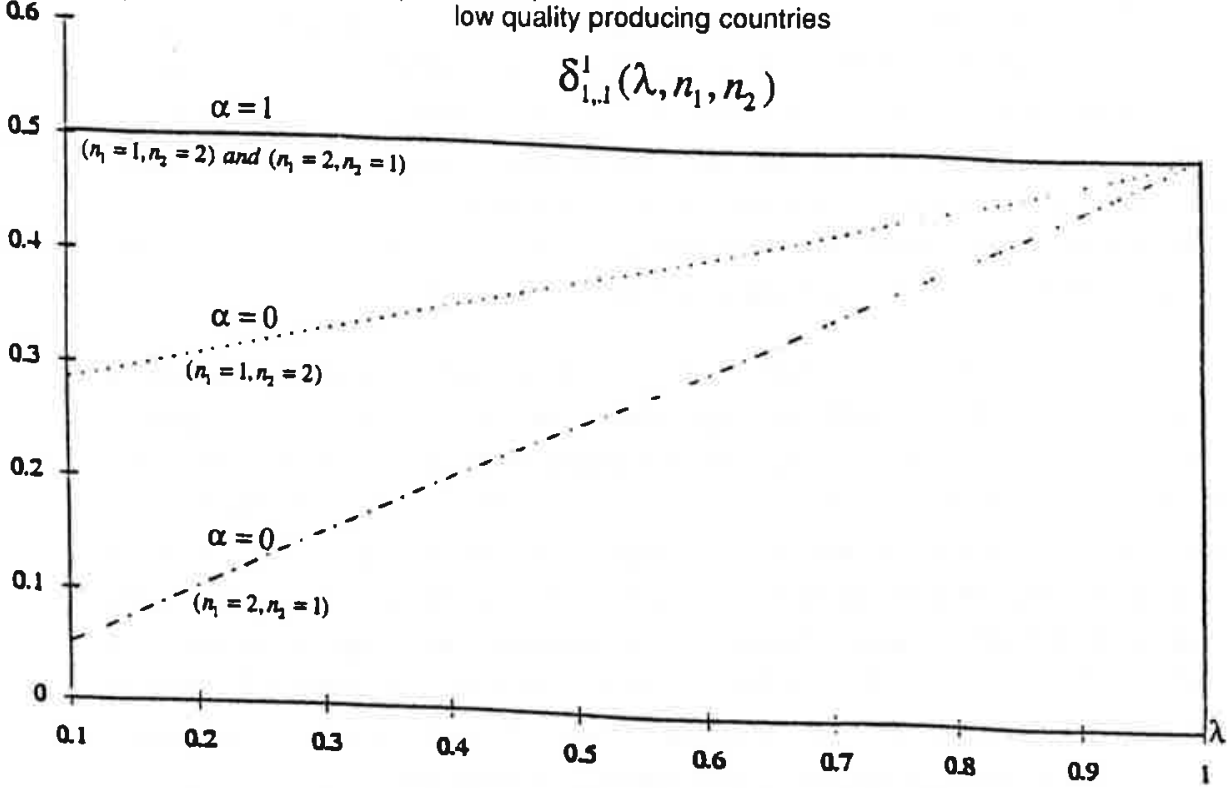

Figure 3 : The relationship between product differentiation and the critical discount rate for high quality producing countries

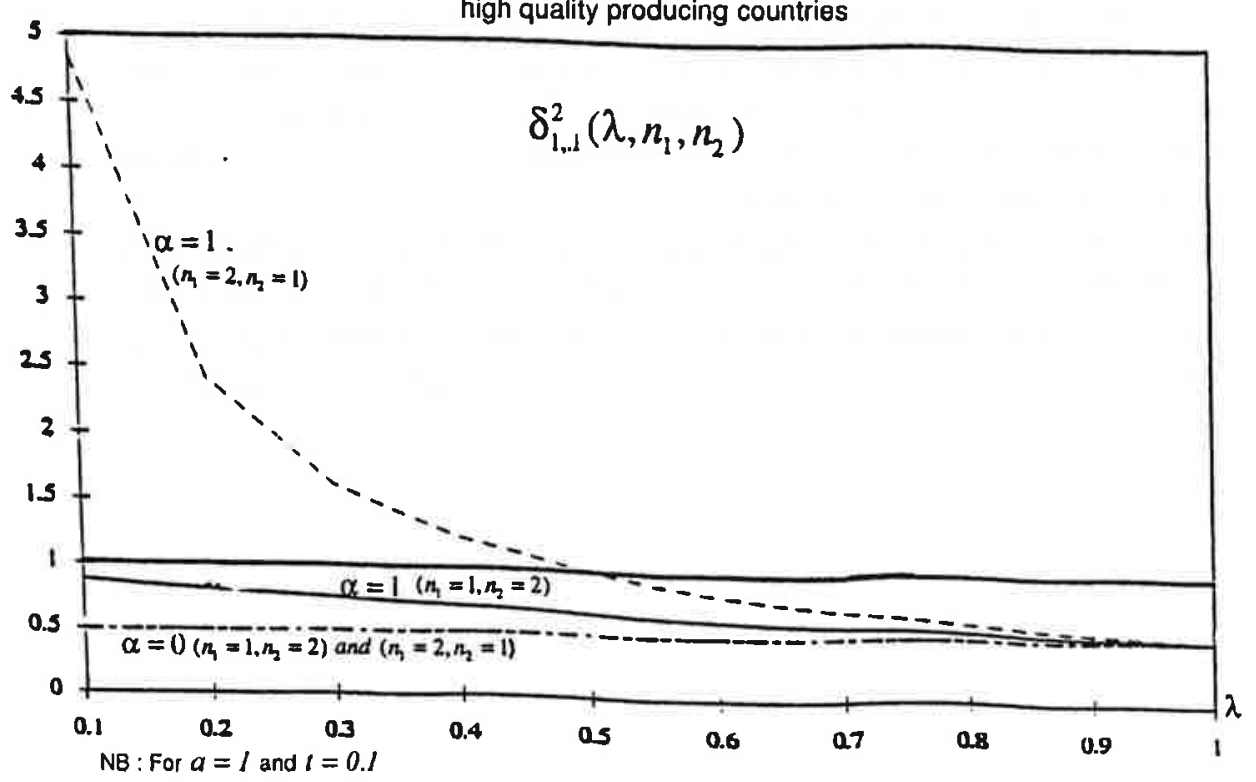

14 
To conclude on this theoretical part, we have shown that greater product heterogeneity does not necessarily weaken the sustainability of collusions. This result, which is consistent with those of Chang (1991) and Ross (1992), is strongly related to the adopted retention scheme. In fact, it has been highlighted that quality-type collusions, implying a non-unilorm retention scheme, are more likely to be supportable when products are highly differentiated. In the case of a unitorm retention scheme, we have emphasised that the impact of product differentiation on the sustainability of a collusion involving all countries is less clear. On one hand, product differentiation deters low quality producing countries defecting but on the other hand, it strengthens the incentive for high quality producing countries to cheat on the cooperative equilibrium. It follows that the collusion will be more likely supportable if the high quality country group is given strong bargaining power in the retention share decision process, which in turn lowers its incentive to defect. 


\section{SOME ISSUES FOR THE WORLD COFFEE MARKET}

Three interesting issues for the world coffee market can be deduced from the above theoretical predictions.

The first one relates to the negative impact of consumer heterogeneity on the sustainability of collusions. In fact, coffee consumer tastes are known to vary a lot among importing countries. For example, Southern European countries such as France and Italy, import nearly as much as robusta than arabica, while Northern European countries such as Finland, Norway and Sweden, import nearly exclusively arabica. Such a consumer differentiation is an important issue for the future of the newly adopted retention scheme, almost if the actual degree of differentiation between arabica and robusta is rather low. Indeed, in that case (as shown in figure 1), a high level of consumer differentiation induces strong incentive, for all producing countries, to cheat on the retention scheme.

The second interesting result lies in the impact of product differentiation on the sustainability of a collusion involving both low and high quality producing countries. This kind of collusion corresponds to the current arrangement on the world coflee market since major robusta and arabica producing countries both agreed on a uniform retention scheme. In view of the sustainability of this retention scheme, the most interesting theoretical result lies in the opposite effects of product differentiation on the respective incentive to cheat for low and high quality producing countries. From this theoretical prediction, it seems that if robusta and arabica coffees are relatively highly differentiated, it would be more likely profitable for robusta producing countries to self-discipline, while arabica producing countries should often face strong incentive to cheat on the retention scheme. Hence, it seems that arabica producing countries hold a power de facto since they are in a position to prevent, through their own doing, the collusion to be supportable. Moreover, it appears that the only way to enhance the sustainability of the collusion is to allow arabica producing countries to set the retention share according to their own profit maximisation. This result is consistent with the commonly held idea among which, before the breakdown of the ICA quota system, Brazil and to a lesser extent Colombia exerted strong power during discussions of export quotas allocation ${ }^{10}$. Therefore, the previous theoretical results suggest that, in a context of product differentiation, giving strong bargaining power to arabica producing countries appears as one way to make the adopted retention scheme more likely to be supportable.

\footnotetext{
10 See Daviron, 1993. Karp and Perlott (1992) also view Brazil and Colombia as a dynamic oligopoly facing a linge with exogeneous exports.
} 
Finally, the third important result concerns the sustainability of quality-type collusions. More precisely, the interesting issue for the world coffee market lies in the fact that under this non-uniform retention scheme, low and high quality producing countries would both face identical incentive to cheat. Furthermore (as shown in figure 1), product differentiation acts as increasing the probability of each quality-type collusion to be sustained. Therefore, this theoretical result suggests that a non-uniform retention scheme among robusta and arabica producing countries could reveal to be a more likely supportable arrangement than the one effectively adopted on the world coffee market. Firstly, the sustainability of such a non-uniform retention scheme is not conditional on an agreement among all countries, regarding the retention share decision process. Secondly, product differentiation favours the sustainability of quality-type collusions (while it strengthens the incentive to cheat on a uniform retention scheme for high quality producing countries).

To conclude, casual evidence suggests that marketing and advertising on coffee is strongly aimed at increasing the degree of differentiation between robusta and arabica. Hence, the product differentiation aspect is likely to be of crucial importance for the future of the world coffee market. 


\section{REFERENCES}

Abreu D., Pearce D., Stachetti D., (1986) - Optimal cartel equilibria with imperfect monitoring. Journal of Economic Theory, 39, pp. 251-269.

Aklyama T., Varangis P., (1991) - Accord international sur le café : Impact sur le marché mondial du système de quotas à l'exportation. In Güvenen O., Labys W. C., Lesourd J. B. (Eds), Politiques économiques et marchés internationaux de matières premières. Economica, Paris, pp. 47-62.

Chang M., (1991) - The effects of Product differentiation on collusive pricing. International Journal of Industrial Organization, 9, pp. 453-469.

Daviron B., (1985) - Chronologie du marché du café : 1929-1983. Document de travail, IAM-LEI, Montpellier.

Daviron B., (1993) - Conflit el coopération sur le marché international du café : Une analyse de longue période. Thèse de Doctorat de l'ENSA Montpellier.

Daviron B., Levin F., (1988) - Recueil d'articles sur le marché mondial du café. Laboratorio de investigacion y desarollo regional, Inireb, Xalapa, Veracruz. IAM Montpellier.

Delaporte G., (1993) - L'accord international sur le café : passé, présent et perspectives, in C. Mouton et E. Colin (eds), Matières premières et échanges internationaux, vol. 6, Economica, Paris, pp. 103-123.

Deneckere R., (1983) - Duopoly Supergames with product differentiation. Economics Letters, 11 , pp. 37-42.

Epps M. L., (1975) - A simulation model of the world colfee economy. In Labys W. C. (Ed), Quantitative models of commodity markets. Ballinger Publishing company, Cambridge, MA, pp. 107-137.

Frledman J., (1971) - A non-cooperative equilibrium for supergames. Review of Economic Studies, 28, pp. 1-12.

Friedman J., (1983) - Oligopoly theory. Cambridge University Press, Cambridge, MA.

Green E., Porter R., (1984) - Noncooperative collusion under imperfect price information. Econometrica, 52, pp. 87-100.

Hermann R., (1991) - Effets redistributifs des accords internationaux de produits vers les pays pauvres. Une analyse économétrique des flux d'aide sous un schéma de quotas d'exportation pour le café. In Güvenen O., Labys W. C., Lesourd J. B. (Eds). Politiques économiques et marchés internationaux de matières premières. Economica, Paris, pp. 63-83.

Karp L. S., Perloff J., (1993) - A dynamic model of Oligopoly in the Coffee Export Market, American Journal of Agricultural Economics, 75, pp. 448-57.

Majerus D., (1988) - Price vs quantity competition in oligopoly supergames. Economics Letters, 27, pp.293-297.

Marshalf C. F., (1983) - The world coffee Trade. A guide to the production, trading and consumption of coffee. Woodhead - Faulkner, Cambridge. 
Motta M., (1993) - Endogeneous quality choice : Price vs quantity competition. The Journal of Industrial Economics, XLI(2), pp. 113-?

Musa M., Rosen S., (1978) - Monopoly and product quality. Journal of Economic Theory, 18, pp. 301-17.

Mwandha J., Sargent M., (1985) - Coffee : The International Commodity Agreement. Cower publishing company.

Okunade A. A., (1992) - Functional forms and habit effects in the US demand for coffee. Applied Economics, 24: 1203-112.

Rlezman R., (1991) - Dynamic tariffs with asymmetric information. Journal of International Economics, 30, pp. 267-283.

Ross T. W., (1992) - Cartel stability and product differentiation. International Journal of Industrial Organisation, 10, pp.1-13.

Rothschlld R., (1993) - Non-cooperative behaviour as a credible threat. Bulletin of Economic research, 37(3), pp. 245-248.

Salant S., Swltzer S., Reynolds R., (1983) - Losses from horizontal merger : The effects of an exogeneous change in industry structure on Cournot-Nash equilibrium. The quarterly Journal of Economics, XCVIII(2), PP. 185-198.

Sengupta J. K., Wang E. C., (1991) - Market structure implications of instability in the world coffee market. Economic Modelling, 8, PP. 102-115. 


\section{APPENDIX11}

\section{A.1. The Quality-type collusions case}

\section{Cooperative equilibrium}

$\pi^{N}$ is the profit function of each collusion $C=N_{j}$, (involving $n$, countries producing quality product $\left.k_{j}\right)$, defined by :

(A1.1) $\pi^{N_{1}}=\sum_{i=1}^{n_{1}}\left(p_{1} q_{i j}-c, q_{1}^{2}\right) \quad j=1,2 \quad$ with $p$, defined by (3)

The first-order condition of each collusion profit maximisation program is given by :

(A1.2) $n_{j} \frac{p_{j}}{k_{j}}=(2 a,+n, l) Q, j=1,2$

where $Q$, is the aggregate supply of quality product $k$,

Plugging (3) into (A1.2) gives the aggregate supply quantities of each collusion :

(A1.3) $\left\{\begin{array}{l}Q_{i}^{\epsilon}=\frac{n_{t}\left(2 a_{2}+n_{2} t\right) \bar{\theta}}{4\left(a_{1}+n_{1} t\right)\left(a_{2}+n_{2} t\right)-\lambda n_{1} n_{2} t^{2}} \\ Q_{2}^{\epsilon}=\frac{n_{2}\left[2 a_{1}+(2-\lambda) n_{t} t\right] \theta}{4\left(a_{1}+n_{1} t\right)\left(a_{2}+n_{2} t\right)-\lambda n_{1} n_{2} t^{2}}\end{array}\right.$

Then the supply quantity of each country i producing quality $k_{j}$ is $: q_{i j}^{c}=\frac{Q,}{n_{j}}$

Defection of country r belonging to collusion $N$,

The best response quantity of country $r$ producing quality product $k_{j}$ is deduced from the first-order condition of her profit maximisation program:

(A1.4) $p_{j}=k_{j}\left(2 a_{j}+1\right) q_{n} j=1,2 \quad r=1, n_{j}$

Using (3) and given that other countries in $N$, leave their production unchanged, the best response quantity of country $r$ producing quality product $k$, is then:

11 Arguments of all Muncions are dropped lor simplicity 
(A1.5)

$$
\left\{\begin{array}{l}
q_{r 1}^{d}=\frac{t}{2\left(a_{1}+t\right)}\left[\frac{\bar{\theta}}{t}-\left(\frac{n_{1}-1}{n_{1}}\right) Q_{t}^{c}-Q_{2}^{c}\right] \\
q_{r 2}^{d}=\frac{t}{2\left(a_{2}+t\right)}\left[\frac{\bar{\theta}}{t}-\lambda Q_{1}^{c}-\left(\frac{n_{2}-1}{n_{2}}\right) Q_{2}^{c}\right]
\end{array}\right.
$$

Each cheated producing country $i_{1}(i \neq r)$ leaves her production unchanged. So:

$q_{1 j}^{v}=\frac{Q_{j}^{c}}{n_{j}}$

Then, the aggregate supply of quality product $k_{j}$ is : $Q_{j}^{v}=\frac{\left(n_{j}-1\right)}{n_{j}} Q_{j}^{c}+q_{n}^{d}$

\section{Cournot-Nash equilibrium}

In this case, the country group $N_{j}$ is at Cournot-Nash equillbrium while the other quality type country group (denoted $N_{-}$) is still at the cooperative equilibrium. Then, using (A1.2) and (A1.4) gives the aggregate Cournot-Nash quantities of both quality products $Q_{h}^{m j}, h=1,2$ :

If $\mid=1$

(A1.6)

$$
\left\{\begin{array}{l}
Q_{1}^{m \prime}=\frac{n_{1}\left(2 a_{2}+n_{2} t\right) \bar{\theta}}{2\left(a_{2}+n_{2} t\right)\left[2 a_{1}+\left(n_{1}+t\right) t\right]-\lambda n_{1} n_{2} t^{2}} \\
Q_{2}^{m \prime}=\frac{n_{2}\left[2 a_{1}+\left(n_{1}-\lambda n_{1}+l\right) t\right] \bar{\theta}}{2\left(a_{2}+n_{2} t\right)\left[2 a_{1}+\left(n_{1}+l\right) t\right]-\lambda n_{1} n_{2} t^{2}}
\end{array}\right.
$$

If $\mathrm{J}=\mathbf{2}$

(A1.7)

$$
\left\{\begin{array}{l}
Q_{1}^{m 2}=\frac{n_{1}\left(2 a_{2}+t\right) \bar{\theta}}{2\left(a_{1}+n_{1} t\right)\left[2 a_{2}+\left(n_{2}+t\right) t\right]-\lambda n_{1} n_{2} t^{2}} \\
Q_{2}^{m 2}=\frac{n_{2}\left[2 a_{1}+n_{1}(2-\lambda) t\right] \bar{\theta}}{2\left(a_{1}+n_{1} t\right)\left[2 a_{2}+\left(n_{2}+t\right) t\right]-\lambda n_{1} n_{2} t^{2}}
\end{array}\right.
$$

\section{A.2. The asymmetric collusion case}

In this case the collusion involves all ( i.e. $n_{1}+n_{2}$ ) countries

The Cournot-Nash equilibrium 
The Cournot-Nash aggregate supply of each quality product is obtained using $(A 1.4)$

(A2.1) $\left\{\begin{array}{l}Q_{i}^{m}=\frac{n_{1}\left(2 a_{2}+l\right) \bar{\theta}}{\left[2 a_{1}+\left(n_{1}+l\right) t\right]\left[2 a_{2}+\left(n_{2}+l\right) t\right]-\lambda n_{1} n_{2} t^{2}} \\ Q_{2}^{m}=\frac{n_{2}\left[\left(2 a_{1}+l\right)+(l-\lambda) n_{l} t\right] \bar{\theta}}{\left[2 a_{1}+\left(n_{1}+l\right) t\right]\left[2 a_{2}+\left(n_{2}+l\right) l\right]-\lambda n_{1} n_{2} t^{2}}\end{array}\right.$

The quantity of quality $k_{j}$ produced by each country $\mathrm{i}\left(i=l, n_{j}\right)$ is then $q_{1 j}^{m}=\frac{Q_{l}^{m}}{n_{j}}$

\section{The cooperative equilibrium}

Each country $i$ retains the same percentage share of her Cournot-Nash production. The optimal retention share $\mu^{*}$ is given by equation (7). Then at cooperative equilibrium, the aggregate supply of each quality product is : $Q_{j}^{c}=\mu^{*} Q_{j}^{m}$ while the corresponding quantity for country $i$ is given by : $q_{i j}^{c}=\mu^{*} q_{i j}^{m}$ for $j=1,2$ and $i=I, n_{j}$.

\section{Defection of country $r$}

Results are identical to those presented in A.1. for the corresponding case. 